This document was prepared in conjunction with work accomplished under Contract No. DE-AC09-96SR18500 with the U. S. Department of Energy.

\title{
DISCLAIMER
}

This report was prepared as an account of work sponsored by an agency of the United States Government. Neither the United States Government nor any agency thereof, nor any of their employees, nor any of their contractors, subcontractors or their employees, makes any warranty, express or implied, or assumes any legal liability or responsibility for the accuracy, completeness, or any third party's use or the results of such use of any information, apparatus, product, or process disclosed, or represents that its use would not infringe privately owned rights. Reference herein to any specific commercial product, process, or service by trade name, trademark, manufacturer, or otherwise, does not necessarily constitute or imply its endorsement, recommendation, or favoring by the United States Government or any agency thereof or its contractors or subcontractors. The views and opinions of authors expressed herein do not necessarily state or reflect those of the United States Government or any agency thereof. 


\section{Trace-level beryllium analysis in the laboratory and in the field: State of the art, challenges, and opportunities}

by

MICHAEL BRISSON

Westinghouse Savannah River Company

Savannah River Site

Aiken, South Carolina 29808

Additional Authors:

This paper was prepared in connection with work done under the above contract number with the U. S. Department of Energy. By acceptance of this paper, the publisher and/or recipient acknowledges the U. S. Government's right to retain a nonexclusive, royalty-free license in and to any copyright covering this paper, along with the right to reproduce and to authorize others to reproduce all or part of the copyrighted paper. 


\title{
Trace-level beryllium analysis in the laboratory and in the field: State of the art, challenges, and opportunities†
}

\author{
Michael J. Brisson, ${ }^{a}{ }^{a}$ Kevin Ashley ${ }^{b}$, Aleksandr B. Stefaniak ${ }^{c}$, Amy A. Ekechukwu ${ }^{d}$ and Kathryn L. \\ Creek $^{e}$
}

\section{${ }_{5}$ Receipt/Acceptance Data [DO NOT ALTER/DELETE THIS TEXT] Publication data [DO NOT ALTER/DELETE THIS TEXT] \\ DOI: 10.1039/b000000x [DO NOT ALTER/DELETE THIS TEXT]}

Control of workplace exposure to beryllium is a growing issue in the United States and other nations. As the health risks associated with low-level exposure to beryllium are 10 better understood, the need increases for improved analytical techniques both in the laboratory and in the field. These techniques also require a greater degree of standardization to permit reliable comparison of data obtained from different locations and at different times. Analysis of low-level beryllium samples, in the form of air filters or surface wipes, is frequently required for workplace monitoring or to provide data to 15 support decision-making on implementation of exposure controls. In the United States and the United Kingdom, the current permissible exposure level is $2 \mu \mathrm{g} / \mathrm{m}^{3}$ (air), and the United States Department of Energy has implemented an action level of $0.2 \mu \mathrm{g} / \mathrm{m}^{3}$ (air) and $0.2 \mu \mathrm{g} / 100 \mathrm{~cm}^{2}$ (surface). These low-level samples present a number of analytical challenges, including (1) a lack of suitable standard reference materials, (2) unknown 20 robustness of sample preparation techniques, (3) interferences during analysis, (4) sensitivity (sufficiently low detection limits), (5) specificity (beryllium speciation), and (6) data comparability among laboratories. Additionally, there is a need for portable, real-time (or near real-time) equipment for beryllium air monitoring and surface wipe analysis that is both laboratory-validated and field-validated in a manner that would be 25 accepted by national and/or international standards organizations. This paper provides a review of the current analytical requirements for trace-level beryllium analysis for worker protection, and also addresses issues that may change those requirements. The current analytical state of the art and relevant challenges facing the analytical community will be presented, followed by suggested criteria for real-time monitoring equipment.

${ }_{30}$ Recognizing and addressing these challenges will present opportunities for laboratories, research and development organizations, instrument manufacturers, and others.

\section{Introduction}

Beryllium is a metal that occurs naturally in beryl and bertrandite mineral deposits. Beryllium is used in a variety of 35 forms and has application in a number of industries, including aerospace, automotive manufacturing, electronics and defense industries, including nuclear weapons ${ }^{1}$. It is also found in consumer goods such as sports equipment ${ }^{2}$. Beryllium may also be encountered as a trace contaminant in raw materials, 40 such as bauxite ore ${ }^{3}$ from which alumina is refined and then

${ }^{a}$ Washington Savannah River Company, Savannah River Site, Aiken, SC, 29808, USA. Fax: +1-803-725-0632; Tel: +1-803-725-3837; E-mail: mike.brisson@srs.gov

${ }^{b}$ National Institute for Occupational Safety and Health, Division of Applied Research and Technology, Cincinnati, OH 45226, USA.

${ }^{c}$ National Institute for Occupational Safety and Health, Division of Respiratory Disease Studies, Morgantown, WV 26505, USA

${ }^{d}$ Savannah River National Laboratory, Aiken, SC 29808, USA.

${ }^{e}$ Los Alamos National Laboratory, Los Alamos, NM 87545, USA.

$\uparrow$ Presented at the Second Symposium on Beryllium Particulates and Their Detection, November 2005, Salt Lake City, UT, USA. This article was prepared by United States Government employees/contractors as part of their official duties and legally may not be copyrighted in the United States of America. processed in aluminum smelters ${ }^{4}$.

Exposure to beryllium salts and beryllium particles in the form of metal, oxide, or alloy can cause an immune system response known as beryllium sensitization (BeS). Exposure 45 may also lead to development of chronic beryllium disease (CBD), a debilitating and potentially fatal progressive lung disease characterized by lesions known as granulomas. BeS is believed to precede development of $\mathrm{CBD}^{5}$. Because CBD can be treated but not cured $^{2}$, exposure monitoring is essential in 50 workplaces where there is potential for beryllium exposure. The need for airborne exposure monitoring was first identified over half a century ago ${ }^{6,7}$. Initially, the intent of airborne monitoring for beryllium was to prevent CBD; however, development of the beryllium lymphocyte proliferation test ${ }_{55}$ (BeLPT) in the late $1980 \mathrm{~s}^{8}$ permitted testing for BeS, which prompted renewed interest in exposure monitoring ${ }^{7}$. It is well known that skin exposure to soluble beryllium salts can cause BeS in humans ${ }^{9}$, and recent evidence suggests that skin contact with poorly soluble beryllium oxide particles can ${ }_{60}$ cause $\mathrm{BeS}$ in mice ${ }^{10}$. Thus, the current prudent approach to worker protection is to assess and minimize both skin and inhalation exposures to beryllium ${ }^{11}$, despite uncertainty with 
regard to which routes of exposure and what levels of airborne and/or skin exposure may lead to BeS and/or CBD, and 65 uncertainty as to what exposure metric best predicts risk.

In recent years, the use of beryllium in the United States has grown considerably; between 1994 and 1998 there was a $21 \%$ increase in beryllium consumption ${ }^{1,12}$. In 1999 the United States Department of Energy (DOE) issued its 70 Beryllium Rule ${ }^{13}$, which introduced a lower action level and increased sampling and analysis requirements at DOE sites, including a requirement for measurement of surface contamination.

The purpose of this paper is to review the history of 75 exposure levels and action limits, and the resulting requirement for greater analytical sensitivity. Current analytical practices will be reviewed, along with an explanation of the need for, and benefits of, harmonization of analytical methods. Additionally, the need for "real-time" 80 measurement capability, especially in field settings, will be discussed. Finally, future analytical challenges will be discussed.

\section{History of Beryllium Occupational Exposure Limits}

${ }_{85}$ Currently, a beryllium inhalation exposure value of $2 \mu \mathrm{g} / \mathrm{m}^{3}$ (eight-hour time-weighted average [TWA]) is used by the American Conference of Governmental Industrial Hygienists (ACGIH ${ }^{\circledR}$ ) as a Threshold Limit Value $(T L V ®)^{14} \ddagger$ and by the United States Occupational Safety and Health Administration 90 (OSHA) as a Permissible Exposure Limit (PEL) ${ }^{15}$. This value is also used as an exposure limit in other countries, including the United Kingdom ${ }^{16}$, Australia ${ }^{70}$, and Ontario, Canada ${ }^{71}$. This limit was originally proposed in 1949 as a result of studies conducted by the United States Atomic Energy ${ }_{95}$ Commission (AEC). This limit was empirically derived due to the lack of a clear exposure-response relationship ${ }^{17}$.

ACGIH ${ }^{\circledR}$ originally proposed the AEC level for beryllium as a TLV® in 1957 and adopted it in 1959. In 1986, the TLV® was applied to beryllium and its compounds. In 1999, 100 ACGIH ${ }^{\circledR}$ proposed a reduction of the TLV® to $0.2 \mu \mathrm{g} / \mathrm{m}^{3}$, but this proposal was never adopted. In 2005 , ACGIH ${ }^{\circledR}$ proposed to reduce the $\mathrm{TLV}{ }^{\circledR}$ to $0.02 \mu \mathrm{g} / \mathrm{m}^{3}$; this proposal was still pending at the time of this writing $^{18}$. These proposed reductions in the TLV® are based on studies such as those by 105 Kreiss et al. ${ }^{19-22}$ and Kelleher et al. ${ }^{23}$, which indicate that the current TLV® is not effective in preventing new cases of CBD. Independently of ACGIH ${ }^{\circledR}$, OSHA is also responding to published study results and is now considering lowering the PEL as part of its current regulatory agenda ${ }^{15,24}$.

110 The DOE, also in response to published studies ${ }^{7,19-22}$, published its Beryllium Rule ${ }^{13}$, published in 1999. The Rule established an action level for airborne exposure of one-tenth the current OSHA PEL, or $0.2 \mu \mathrm{g} / \mathrm{m}^{3}$. An empirical action level of $0.2 \mu \mathrm{g} / 100 \mathrm{~cm}^{2}$ was established for surface wipes as a 115 criterion for release of equipment to the public or "nonberyllium areas". In addition, a value of $3 \mu \mathrm{g} / 100 \mathrm{~cm}^{2}$ was established as a "housekeeping" action level for surfaces within beryllium work areas.
The actions of ACGIH ${ }^{\circledR}$, OSHA, and DOE indicate that 120 despite the continuing lack of an exposure-response relationship for $\mathrm{CBD}$, the current trend in professional practice and regulatory efforts is clearly toward lower empirical mass-based limits and action levels. As will be described in the following sections, this trend presents many 125 challenges to current analytical capabilities.

\section{State of the Analytical Art}

\section{Available Techniques}

Analysis techniques commonly used in the United States and United Kingdom for beryllium at trace levels include 130 inductively coupled plasma atomic emission spectroscopy

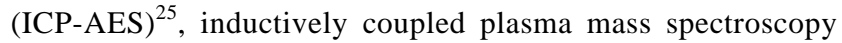
$(\mathrm{ICP}-\mathrm{MS})^{26}$, and atomic absorption spectroscopy (AAS) ${ }^{27}$. Additionally, an atomic fluorescence method has recently been developed ${ }^{28-30}$. Estimates of method detection limits 135 (MDLs) for these techniques are given in Table $1^{30,31}$. At first glance, the values cited in Table 1 appear to be adequate for current action levels, and even for the recently proposed ACGIH® TLV®. However, it is necessary for the MDL to be well below the applicable exposure limit or action level; a 140 value of ten percent of the applicable exposure limit or action level is a typical goal. This requirement ensures that the analyte concentration can be measured quantitatively at the exposure limit or action level. Given the trend toward lower action levels, current techniques will continue to be 145 challenged to meet increasingly demanding performance expectations.

In selecting one or more techniques to use, laboratories must consider a number of factors, including instrument cost, type(s) of samples analyzed (i.e., air filters or surface wipes or 150 both), physical and chemical forms of beryllium anticipated (as discussed further below), and interferences that may be encountered. For example, ICP-MS is more sensitive than ICP-AES, and is thus a good choice for analysis of air filters, but it is significantly more expensive. However, because ICP155 MS may be more affected by sample matrix effects such as those typically encountered with surface wipes, this technique may not be as good a choice for analysis of surface wipes as ICP-AES. On the other hand, ICP-AES is subject to spectral interferences with all three of the primary lines used for 160 beryllium (see Table 2) ${ }^{32,33}$. While there are established techniques for interference correction ${ }^{34}$, high concentrations of intereferences can impact analytical sensitivity. For both ICP-AES and ICP-MS, appropriate matrix matching is important.

165 Because the atomic fluorescence method for trace-level beryllium is a relatively new application, field experience is limited. However, interlaboratory validation results suggest that this technique holds promise because it has comparable sensitivity to ICP-MS ${ }^{28}$ and is less subject to interference ${ }_{170}$ effects $^{29}$. Other techniques that have been, or are currently, under consideration are discussed under "Alternative Techniques.”

\section{Sample Preparation}


${ }_{175}$ Once samples are collected on air filters or surface wipes, the beryllium is brought into solution, by digestion or extraction, prior to instrumental analysis. The ICP-AES, ICP-MS, and AAS methods rely on sample preaparation by an acid digestion involving one or more acids in combination with 180 heat. A wide variety of digestion protocols are used ${ }^{33}$, making it difficult to compare analytical results among laboratories even when the same instrument is used. The fluorescence method uses a $1 \%$ ammonium bifluoride (aqueous) extraction $^{28,29}$.

185 For sample preparation by acid digestion, the main consideration in selecting a digestion protocol is to ensure that it is sufficiently robust to digest all of the beryllium present in the sample, regardless of the chemical forms or physical characteristics (such as particle size). An additional 190 consideration is selection of the method of heating the sample; accepted means include hot plate, hot block, and microwave digestion. Laboratories that analyze air filter samples, but not surface wipes, may not require an extremely aggressive digestion protocol. The same is true for laboratories whose 195 samples contain exclusively soluble forms of beryllium. For such laboratories, a single acid (nitric acid or sulfuric acid) may suffice for their purposes.

However, there is a particular concern when samples may contain refractory beryllium oxide $(\mathrm{BeO}) \S$. For example, 200 sulfuric acid is generally effective for $\mathrm{BeO}$ but is problematic for some sampling media ${ }^{35}$. Some acids, such as hydrofluoric acid and perchloric acid, are effective for a variety of media and for $\mathrm{BeO}$, but may not be desirable due to safety concerns. Particle size distribution also plays a role in the efficacy of 205 digestion protocols ${ }^{36}$. Most DOE sites where this is a concern use a mixture of acids at varying concentrations ${ }^{33}$. There is limited, but not sufficient, data in the literature on the efficacy of various digestion protocols for high-fired $\mathrm{BeO}^{36}$, especially with regard to $\mathrm{BeO}$ having a range of particle sizes. 210 Extraction by 1\% ammonium bifluoride, when heated to $\sim 85^{\circ} \mathrm{C}$, has shown quantitative recovery for $\mathrm{BeO}$ (particle size unknown) up to $2 \mu \mathrm{g} / \mathrm{sample}$, but is less consistent at levels in the 10-20 mg range. Recoveries are also reduced when some surface wipes, such as GhostWipes ${ }^{\mathrm{TM}}$ (Environmental 215 Express, Charleston, SC, USA, www.envexp.com), are used ${ }^{30}$.

The lack of a $\mathrm{BeO}$ reference material is an additional complicating issue. Reference materials are required to provide a definitive evaluation of digestion and extraction protocols for their effectiveness with $\mathrm{BeO}^{37}$. In the United 220 States, a cooperative effort involving DOE, the National Institute for Occupational Safety and Health (NIOSH), and the National Institute of Standards and Technology (NIST) has been initiated to establish one or more $\mathrm{BeO}$ reference materials $^{38}$.

\section{Accreditation and Quality Assurance}

Laboratories analyzing beryllium in workplace monitoring samples typically require accreditation and/or demonstration of proficiency. For example, the U. K. Health and Safety Laboratory administers the Workplace Analysis Scheme for 230 Proficiency (WASP) with participation by over 200 laboratories worldwide ${ }^{72}$. The WASP scheme includes several metals but not beryllium specifically. In the United
States, the American Industrial Hygiene Association (AIHA) administers an accreditation program that is used by most 235 industrial hygiene laboratories. AIHA accreditation requirements $^{39}$ are based on the requirements of Standard 17025 of the International Organization for Standardization $(\mathrm{ISO})^{40}$. ISO 17025 includes requirements for documentation that appropriate management, technical, and personnel 240 qualification requirements are met. It is also required that accreditation teams ("site assessors") visit participating laboratories periodically.

AIHA also administers a Beryllium Proficiency Analytical Testing (BePAT) program. One issue that has emerged with 245 the BePAT program is that the form of beryllium used in the proficiency samples is beryllium acetate, which is watersoluble and thus easy to digest. Establishing a $\mathrm{BeO}$ reference material will allow development of BePAT samples based on $\mathrm{BeO}$ rather than beryllium acetate, which would provide a 250 more robust test of digestion protocols.

It is important to note that accreditation, while a necessary and valuable function for assuring the quality of laboratory results, is not a guarantee that different laboratories will always produce the same results on the same samples. For 255 example, in 2002, DOE's Savannah River Site (SRS) sent split samples to two AIHA-accredited laboratories. These laboratories, both of which used ICP-AES, reported different results although both laboratories were using the same analytical method. The discrepancies were found to be due to 260 disparities in spectral interference corrections, which caused one of the laboratories to under-report the beryllium content. Questions also arose about the robustness of the sample preparation. After this, SRS began using hydrofluoric acid as one of the acids in its sample preparation protocol ${ }^{41}$.

265 It should also be noted that, at the time of this writing, the atomic fluorescence method is not specifically sanctioned by AIHA as an approved "field of testing" for beryllium. To address this gap, some organization wishing to use fluorescence within AIHA accreditation space will need to 270 apply to AIHA to add fluorescence as a "field of testing" for laboratory and/or field applications Other sites could then include the method, as sanctioned by AIHA, within their standard accreditation process.

\section{Alternative Techniques}

275 A variety of alternative techniques for sampling and analysis of beryllium have been attempted. Most of these are directsolid measurement techniques that may provide faster results than fixed-site laboratory-based methods. These techniques also avoid the sample preparation requirements and associated 280 liquid waste generation of more traditional analytical techniques, and could potentially be made field-portable. These techniques include laser induced breakdown spectroscopy (LIBS) ${ }^{42}$, microwave induced plasmas spectroscopy (MIPS) ${ }^{43,44}$, aerosol time of flight mass 285 spectroscopy (TOFMS) ${ }^{45}$, and surface enhanced Raman spectroscopy (SERS) ${ }^{46}$.

Although there is substantial interest in these techniques, none of them has as yet gained wide acceptance for several reasons. First, there are issues with analytical precision at the 290 low levels required by the DOE action limit (and the proposed 
ACGIH ${ }^{\circledR}$ TLV $\left.{ }^{\circledR}\right)$; DOE requires a precision of $\pm 25 \%$ at the $0.2 \mu \mathrm{g} / \mathrm{sample}$ action level ${ }^{13}$. Second, method development using these techniques has mostly been targeted toward analysis of air filters, and has not considered the requirement 295 of the DOE Beryllium Rule for analysis of surface wipes. Finally, these methods have not yet received the amount of interlaboratory evaluation and field validation that has been performed with the atomic fluorescence method ${ }^{28}$ and the traditional laboratory methods (ICP-AES, ICP-MS, AAS). 300 Since the Beryllium Rule has given focus to beryllium sampling and analysis within DOE, many of these efforts have been fostered by DOE national laboratories ${ }^{33}$. Resolution of the issues needed for these methods to gain further acceptance will require a more coordinated and expanded effort, with 305 targeted funding.

\section{Method Harmonization}

Pursuant to publication of the DOE Beryllium Rule ${ }^{13}$, efforts to comply with the Rule, including attempts to compare data from various laboratories, identified a need for greater method 310 standardization $^{31}$. As shown in Tables 3 and 4, published sample preparation and analysis methods for worker protection and/or environmental samples are available from several sources ${ }^{25-27,47-57}$. In the United States, these include the American Society for Testing and Materials (ASTM) 315 International, the United States Environmental Protection Agency (EPA), NIOSH, and OSHA. Internationally, some standard methods are available from ISO, the United Kingdom Health and Safety Executive (HSE), and the French Institut National de Recherche et de Sécurité (INRS).

320 With regard to sample preparation, there are gaps in the available standard methods (see Table 3). In particular there are United States governmental methods for acid digestion of surface wipes and bulk samples, but no consensus standards are available. Many laboratories have found it necessary to 325 modify the "standard" digestion methods to assure robustness for the samples they encounter ${ }^{33}$. Availability of $\mathrm{BeO}$ reference materials would aid in forming an improved basis for standard digestion methods ${ }^{37}$. Additionally, there are standard extraction methods, developed for environmental 330 samples, available from ASTM International and EPA; these could be candidates for consideration in beryllium sample preparation. With regard to sample analysis, available standard methods are summarized in Table 4 . Despite the availability of many governmental methods for the various 335 sample types and analysis techniques, there is a lack of consensus standards for analysis of surface wipes and bulk samples.

Within the United States, efforts to address these gaps, as well as those in beryllium sampling methods, have begun 340 under a cooperative effort involving ASTM International, Subcommittee D22.04 on Workplace Atmospheres, and the Beryllium Health and Safety Committee (BHSC)ף. The recently-published fluorescence $\operatorname{method}^{52}$ is an example of this fruitful collaboration. At the time of this writing, efforts 345 were underway to revise ASTM D7035, which is an ICP-AES method $^{25}$, to include ICP-MS for beryllium and other selected analytes. Once a $\mathrm{BeO}$ reference material is established, efforts toward more consistent sample preparation methods can be pursued.

350 A fertile opportunity exists, but is not yet being addressed, for harmonization of United States and international standard methods. This opportunity extends to related areas that are outside the scope of this paper, such as beryllium sampling methods for both air sampling and surface wiping ${ }^{31}$. For 355 example, consensus is needed on which air fraction should be sampled (i.e., inhalable or respirable), and whether to wipe the inside of the air filter cassette ${ }^{58}$. Cooperation among various international standardization organizations to address these opportunities would be beneficial.

\section{${ }_{360}$ Need for "Real-Time" Analysis in the Field}

Current analytical techniques, with the exception of the fluorescence method, are lagging indicators based on results from stationary laboratories. While most laboratories can analyze "rush" samples within a few hours, it is more typical 365 for laboratories to take at least 24 hours from time of sample receipt, and often longer, to provide analysis results. This length of time results from a combination of sample volume and competition with other analysis requirements. Several sites surveyed by the BHSC in 2004 analyze tens of thousands 370 of samples per year ${ }^{33}$. Typically these laboratories perform a variety of other environmental and/or workplace monitoring analyses that compete for laboratory resources. For DOE sites alone, the sampling and analysis costs are in the millions of United States dollars per year. Analysis costs are particularly 375 high for radiologically contaminated samples, which represent about $19 \%$ of the total among sites participating in the 2004 survey $^{33}$. In some cases, waiting for the results causes delays in operations and additional costs. As a result, there is a need for the capability to perform these analyses faster, in or near 380 real time, preferably using a field-portable application. For the sake of simplicity, the term "real-time monitor" is used in the balance of this discussion to refer to field-portable instrumentation that can deliver such results for air filters and/or surface wipes in, or near, real time.

385 Interest in real-time monitors began crystallizing in the late 1990s as it became evident that the $2 \mu \mathrm{g} / \mathrm{m}^{3}$ PEL was not preventing new cases of CBD, that DOE would soon establish lower action levels, and that substantial savings in analytical and operating costs could be achieved with such equipment. 390 A symposium on Beryllium Particulates and Their Detection was held in February 2002 where a number of candidate techniques were presented ${ }^{59}$. At this symposium, papers were presented on techniques utilizing LIBS, MIPS, TOFMS, voltammetry $^{60,61}$ and colorimetric surface wipes ${ }^{62}$. The LIBS,

395 MIPS, and colorimetric techniques are now commercially available ${ }^{42,44,63}$, along with the atomic fluorescence technique developed more recently ${ }^{28-30}$.

In 2002-03, a group of scientists from DOE, NIOSH, and the U. S. Department of Defense (DOD) developed 400 preliminary criteria for real-time air monitoring equipment and surface wipe analyzers ${ }^{59,64}$. These criteria include essential functionalities for beryllium measurement and data reporting, throughput, portability requirements, and validation through technical and field evaluations. To date, most of the 
405 technologies previously described meet at least some of these criteria, but none fulfill all of these requirements. Thus, additional research and development work is needed, and better coordination and funding of that effort would help achieve the desired results.

410 A potential limitation of real-time monitoring is that the results could only be used for screening purposes unless the equipment, and the equipment operator, are accredited (e.g., by $\mathrm{AIHA}^{39}$ ). With respect to AIHA accreditation, any realtime monitor would need to be added as a "field of testing" if

415 the results are intended to be used in the same way that accredited laboratory results would be used. This process may raise some issues since field equipment is typically not operated by laboratory personnel, and field personnel typically are not included in laboratory applications for AIHA 420 accreditation. However, there is a precedent in the United States for recognizing the use of field instrumentation in accreditation programs (i.e., the Environmental Lead Laboratory Accreditation Program $[E L L A P]^{39}$ ).

\section{Future Analytical Challenges}

${ }_{425}$ Fulfillment of a number of information gaps regarding exposure to beryllium will have an impact on the future analytical science for measuring trace levels of beryllium in the workplace. A protective occupational exposure limit, based on human epidemiology, is needed for measurement of 430 total beryllium mass to be of maximum benefit. It should be pointed out that compliance with an occupational exposure limit is only one of many uses for sampling and analysis results. Other crucial uses include epidemiological studies, hazard evaluations, characterization of emissions or legacy 435 contamination areas, and investigation of the efficacy of control measures. The most appropriate metric for prevention of CBD is currently unclear and is an active area of research. For analysis of air samples, potential metrics include total aerosol mass with or without regard to particle size, particle ${ }_{440}$ surface area $^{65}$, particle number ${ }^{66}$, bioavailable beryllium based on particle physicochemical properties ${ }^{67}$, or some combination thereof.

As noted previously, current occupational exposure limits are based on total beryllium aerosol mass, independent of 445 chemical form. Additional studies are needed to confirm this understanding, and to identify whether some chemical forms of beryllium pose a greater risk of $\mathrm{BeS}$ and CBD than others. Clarification of the relative risk associated with exposure to the various chemical forms of beryllium will impact future 450 analytical science. At present, it is generally accepted that exposure to beryllium metal, alloys, and $\mathrm{BeO}$ causes $\mathrm{BeS}$ and/or CBD, whereas exposure to naturally-occuring forms such as beryl and bertrandite has not yet been associated with adverse health effects ${ }^{68}$. Thus, future analytical needs may 455 include development of analytical protocols capable of differentiating among beryllium species. One possibility is a sequential digestion scheme such as that described by Profumo et al. ${ }^{69}$.

\section{Conclusions}

460 While considerable progress has been made in trace-level beryllium analysis, particularly in the last ten years, much more remains to be done to meet the needs of the industrial hygiene community. Specifically, we need to be sure we are measuring the correct exposure metric(s), and at the 465 appropriate action levels. We need to continue pursuit of a $\mathrm{BeO}$ reference material as a means to validate sample preparation methods and improve proficiency testing programs. We need to more aggressively pursue harmonization of methods, both within the United States and 470 internationally, to assure comparability of data. Finally, we need coordinated development of field-portable beryllium measuring equipment so that more of the analyses can be shifted from fixed-site laboratories to the field, thereby speeding decision-making and reducing costs.

\section{${ }_{475}$ Acknowledgements}

The authors gratefully acknowledge the assistance of members of the BHSC Sampling and Analysis Subcommittee, which has coordinated much of this work. We also acknowledge the efforts of Tom Oatts, Mark Hoover, Gregory 480 Turk, and Robert Watters toward establishing BeO reference materials. The support of Steven Jahn and Marion Hook at Savannah River Site is acknowledged. Finally, the reviewers of the draft manuscript, including Martin Harper, Mark Millson and Gene Kennedy of NIOSH, and the referees, are 485 gratefully acknowledged.

\section{Disclaimers}

Mention of commercial products in this review does not imply endorsement by the authors, their companies, or any agency of the United States government.

490 The findings and conclusions in this paper have not been formally disseminated by the National Institute for Occupational Safety and Health and should not be construed to represent any agency determination or policy.

\section{Notes and references}

$495 \ddagger$ ACGIH ${ }^{\circledR}$ publishes a "Statement of Position Regarding the TLVs ${ }^{\circledR}$ and BEIs ${ }^{\circledR}$ ” available at http://www.acgih.org. This statement indicates that $\mathrm{TLVs}{ }^{\circledR}$ are health-based values that represent ACGIH's ${ }^{\circledR}$ scientific opinion of a value below which nearly all workers may be repeatedly exposed without adverse health effects. Regulatory bodies should 500 consider these values as input into the risk characterization process, but should also analyze additional factors before adopting a TLV ${ }^{\circledR}$ as a regulatory standard.

$\S$ Beryllium silicates and aluminosilicates typically require a more robust digestion than does beryllium oxide; however, these forms are not 505 typically encountered by industrial hygiene laboratories.

If The Beryllium Health and Safety Committee (BHSC) is an ad hoc group consisting of members from DOE sites, other U.S. government agencies such as NIOSH, OSHA, and the Department of Defense, and from the U.K. Atomic Weapons Establishment (AWE). Information on 510 the BHSC may be obtained at http://www.sandia.gov/BHSC.

1 Toxicological Profile for Beryllium, U.S. Agency for Toxic Substances and Disease Registry, 2002.

2 About Beryllium, Department of Energy Chronic Beryllium Disease 515 Prevention Program, US Department of Energy, Washington, DC, URL: http://www.eh.doe.gov, accessed 30 March 2006. 
3 V. N. Lavrenchuk and E. K. Mikhailova, Geochem. Int. USSR, 1964 4, 667-669.

4 Y. Thomassen, N. P. Skaugset, K. Dahl, I. Martinsen, D. G. $520 \quad$ Ellingsen, L. Jordbekken, and P. A. Drabløs, Beryllium Exposure Assessment in Primary Aluminum Production: Sampling and Measurement, presented at ASTM International Symposium on Beryllium: Sampling and Analysis, Reno, NV, USA, April 2005.

5 L. S. Newman, M. M. Mroz, R. Balkissoon, and L. A. Maier, Am. J. 525 Respir. Crit. Care Med., 2005, 171, 54-60.

6 J. H. Sterner and M. Eisenbud, A.M.A. Arch. Ind. Hyg. and Occup. Med., 1951, 4, 123-151.

7 M. Eisenbud, Appl. Occup. Environ. Hyg., 1998, 13, 25-31.

8 M. D. Rossman, J. A. Kern, J. A. Elias, M. R. Cullen, P. E. Epstein,

530 O. P. Preuss, T. N. Markham, and R. P. Daniele, Ann. Int. Med., 1988, 108, 687-693.

9 G. H. Curtis, Arch. Dermat. Syph., 1951, 64, 470-482.

10 S. S. Tinkle, J. M. Antonini, B. A. Rich, J. R. Roberts, R. Salmen, K. DePree, and E. J. Adkins, Environ. Health Perspect., 2003, 111, 1202-1208.

11 G. A. Day, A. B. Stefaniak, A. Weston, and S. S. Tinkle, Int. Arch. Occup. Environ. Health, 2005, 79, 161-164.

12 L. D. Cunningham, Beryllium, Mineral Commodity Summary, U.S. Geological Survey, 1999.

54013 U.S. Code of Federal Regulations, Title 10, Part 850.

$14 T L V s \AA$ and $B E I S \AA$, American Conference of Governmental Industrial Hygienists, 2005.

15 Federal Register, November 26, 2002, 67, 70707-70712.

16 List of Workplace Exposure Limits (WELS) and Other Tables, U. K.

545 Health and Safety Commission, HSC/04/06 Annex C, 2004.

17 M. Eisenbud, Environ. Res., 1982, 27, 79-88.

18 Notice of Intended Changes Draft Documentation for Beryllium and Compounds, American Council of Governmental Industrial

550 Hygienists, 2005. Used with permission.

19 K. Kreiss, S. Wasserman, M. M. Mroz, and L. S. Newman, J. Occup. Med., 1993, 35, 267-274.

20 K. Kreiss, M. M. Mroz, B. Zhen, J. W. Martyny, and L. S. Newman, Am. Rev. Respir. Dis., 1993, 148, 985-991.

55521 K. Kreiss, M. M. Mroz, L. S. Newman, J. Martyny, and B. Zhen, Am. J. Ind. Med., 1996, 30, 16-25.

22 K. Kreiss, M. M. Mroz, B. Zhen, H. Wiedemann, and B. Barna, Occup. Environ. Med., 1997, 54, 605-612.

23 P. C. Kelleher, J. W. Martyny, M. M. Mroz, A. J. Ruttenber, D. A.

560 Young, and L. S. Newman, J. Occup. Environ. Med., 2001, 43, 238249.

24 Semiannual Regulatory Agenda, U.S. Occupational Safety and Health Administration, Federal Register, October 31, 2005, 70, 64896.

25 ASTM Standard D7035, Standard Test Method for Determination of

565 Metals and Metalloids in Airborne Particulate Matter by Inductively Coupled Plasma Atomic Emission Spectrometry, ASTM International, West Conshohocken, PA, October 2004.

26 EPA 6020, "Inductively Coupled Plasma - Mass Spectrometry", in Publication SW-846, Test Methods for Evaluating Solid Waste, Physical/Chemical Methods. US Environmental Protection Agency, Washington, DC, 1996, URL: http://www.epa.gov/epaoswer/hazwaste/test/sw846.htm, accessed 17 January 2006.

27 Method 7102, Issue 2, "Beryllium and Compounds, as Be", in

575 NIOSH Manual of Analytical Methods, Fourth Edition, 2003, URL: http://www.cdc.gov/niosh/nman, accessed 24 January 2006.

28 K. Ashley, T. M. McCleskey, M. J. Brisson, G. Goodyear, J. Cronin, and A. Agrawal, J. ASTM Int., 2005, 2(9), DOI 10.1520/JAI13156.

29 E. M. Minogue, D.S. Ehler, A. K. Burrell, T. M. McCleskey, and T. P. Taylor, J. ASTM Int., 2005, 2(9), DOI 10.1520/JAI13168.

30 A. Agrawal, J. Cronin, J. Tonazzi, T. M. McCleskey, D. S. Ehler, E. M. Minogue, G. Whitney, C. Brink, A. K. Burrell, B. Warner, M. J. Goldcamp, P. C. Schlecht, P. Sonthalia, and K. Ashley, "Validation of a Standardized Portable Fluorescence Method for Determining

585 Trace Beryllium in Workplace Air and Wipe Samples”, J. Environ. Monit., submitted.
31 K. Ashley, M. J. Brisson, and S. D. Jahn, J. ASTM Int., 2005, 2, DOI 10.1520/JAI13169.

32 R. K. Winge, V. A. Fassel, V. J. Peterson and M. A. Floyd, in Inductively Coupled Plasma-Atmoic Emission Spectroscopy, Elsevier, Amsterdam, 1985, pg. 266.

33 M. J. Brisson, A. A. Ekechukwu, K. Ashley, and S. D. Jahn, J. ASTM Int., 2006, 3(1), DOI 10.1520/JAI13157.

34 M. Thompson and R. M. Barnes, in Inductively Coupled Plasmas in 595 Analytical Atomic Spectrometry, VCH Publishers, New York, 1992, pp. 276-297.

35 C. J. Coleman, A. R. Jurgensen, D. R. Click, J. C. Hart, R. L. Rutherford, W. M. Smith, T. L. White, B. H. Burch, and D. M. Missimer, Evaluation of High-Fired Beryllium Oxide Digestion Methods to Measure Beryllium in Industrial Hygiene Samples by Inductively Coupledb Plasma Atomic Emission Spectrocopy. Savannah River National Laboratory Technical Report No. WSRCTR-2004-00395, Rev. 1, Aiken, SC, USA, November 2004.

36 A.B. Stefaniak, M. D. Hoover, G. A. Day, A. A. Ekechukwu, G. E. Whitney, C. A. Brink, and R. C. Scripsick, J. ASTM Int., 2005, 2, DOI 10.1520/JAI13174.

37 R. L. Watters Jr., M. D. Hoover, G. A. Day, and A. B. Stefaniak, J. ASTM Int., 2006, 2(9), DOI 10.1520/JAI13171.

38 M. J. Brisson, K. Ashley, M. D. Hoover, G. C. Turk, T. J. Oatts, and 610 A. B. Stefaniak, Role of a Beryllium Oxide Reference Material in Development and Harmonization of Standard Methods, abstract for Tenth Symposium on Biological and Environmental Reference Materials, Charleston, SC, USA, April 2006, submitted.

39 Laboratory Quality Assurance Programs Document, American 615 Industrial Hygiene Association, April 200, URL: http://www.aiha.org, accessed 17 January 2006.

40 ISO/IEC Standard 17025, General requirements for the competence of testing and calibration laboratories, International Organization for Standardization, Geneva, Switzerland, 2005.

62041 P. Cable-Dunlap, A. Guanlao, E. Kahal, S. LaMont, C. Shick, and S. Jahn, Beryllium Wipe Analysis - SRS Lessons Learned, Savannah River Site Report No. SRT-NTS-2003-00088, US Department of Energy, Washington, DC, URL: http://www.eh.doe/gov/ll, accessed 21 January 2005.

62542 W. Pierce, S. M. Christian, M. J. Myers, and J. D. Myers, Fieldtesting for environmental pollutants using briefcase sized portable LIBS system, presented at Third International Conference on Laser Induced Plasma Spectroscopy and Applications, Málaga, Spain, 2004.

63043 Y. Su, Z. Jin, Y. Duan, M. Koby, V. Majidi, J. A. Olivares, and S. P. Abeln, Anal. Chim. Acta, 2000, 422, 209-216.

44 Y. Duan, Y. Su, Z. Jin, and S. P. Abeln, Anal. Chem., 2000, 72, 1672-1679.

45 S. S. Cristy, "Evaluation of an Aerosol Time-of-Flight Mass 635 Spectrometer for Industrial Monitoring”, J. Environ. Monit., submitted.

46 T. Vo-Dinh, M. Martin, and B. Phifer, Real-Time Surface Contamination Monitor for Beryllium Oxide Particulates, presented at Second Symposium on Beryllium Particulates and Their Detection, Salt Lake City, UT, USA, November 2005.

47 Method 7300, Issue 3, "Elements by ICP", in NIOSH Manual of Analytical Methods, Fourth Edition, 2003, URL: http://www.cdc.gov/niosh/nman, accessed 24 January 2006.

48 Methods ID-125G and ID-206, in OSHA Sampling and Analytical 645 Methods, US Occupational Safety and Health Administration, Salt Lake City, UT, 2003, URL: http://www.osha.gov/dts/stlc/methods/toc.html, accessed 30 March 2006.

49 Method MDHS 29/2, Methods for the Determination of Hazardous Substances, U.K. Health and Safety Executive, London, 1996.

50 Method INRS Fiche 003, Métrologie des Polluants - Evaluation de l'Exposition Professionnelle - Méthodes de Prélèvement et d'Analyse de l'Air, Institut National de Recherche et de Sécurité (INRS), Paris, 2004, URL: http://www.inrs.fr, accessed 30 March 2006.

65551 ISO Standard 15202, Workplace Air - Determination of Metals and Metalloids in Airborne Particulate Matter by Inductively Coupled 
Plasma Atomic Emission Spectrometry, International Organization for Standardization, Geneva, Switzerland, 2001.

52 ASTM Standard D7202, Standard Test Method for Determination of 660 Beryllium in the Workplace Using Field-Based Extraction and Fluorescence Detection, ASTM International, West Conshohocken, PA, November 2005.

53 Method 7303, “Elements by ICP (Hot Block/HCl/ $\mathrm{HNO}_{3}$ Digestion)”, in NIOSH Manual of Analytical Methods, Fourth Edition, 2003,

665 URL: http://www.cdc.gov/niosh/nman, accessed 24 January 2006.

54 Method 9102, "Elements on Wipes”, in NIOSH Manual of Analytical Methods, Fourth Edition, 2003, URL: http://www.cdc.gov/niosh/nman, accessed 27 January 2006.

55 Method 6010B, "Inductively Coupled Plasma - Atomic Emission Spectrometry", in Publication SW-846, Test Methods for Evaluating Solid Waste, Physical/Chemical Methods. US Environmental Protection Agency, Washington, DC, 1996, URL: http://www.epa.gov/epaoswer/hazwaste/test/sw846.htm, accessed 17 January 2006.

67556 Method 200.7, "Metals and Trace Elements - ICP-AES", US Environmental Protection Agency, Washington, DC, 1994.

57 Method 200.8, “Trace Elements in Water and Wastes - ICP-MS”, US Environmental Protection Agency, Washington, SC, 1994.

58 M. Harper, "Inhalable Sampling of Aerosols with Special Reference 680 to Beryllium”, J. Environ. Monit., submitted.

59 K. L. Creek and M. J. Brisson, Beryllium Advanced Technology Assessment Team: A Final Report, presented at ASTM International Symposium on Beryllium: Sampling and Analysis, Reno, NV, USA April 2005.

68560 J. Wang and B. Tian, Anal. Chim. Acta, 1992, 270, 131-141.

61 C. Jolly, On-Site Voltammetric Analysis of Beryllium in Dust and Air Samples, presented at (First) Symposium on Beryllium Particulates and Their Detection, Santa Fe, NM, USA, February 2002.

62 T. P. Taylor and N. N. Sauer, J. Hazard. Mater., 2002, 93, 271-283.

69063 T. M. Tekleab, G. M. Mihaylov, and K. S. Kirollos, “Onsite directread system for semi-quantitative detection of traces of beryllium on surfaces”, J. Environ.. Monit., submitted.

64 M. J. Brisson and K. L. Creek, Criteria for Real-Time Beryllium Monitoring Equipment, presented at Second Symposium on

695 Beryllium Particulates and Their Detection, Salt Lake City, UT, USA, November 2005.

65 A. B. Stefaniak, M. D. Hoover, R. M. Dickerson, E. J. Peterson, G. A. Day, P. N. Breysse, M. S. Kent, and R. C. Scripsick, Am. Ind. Hyg. Assoc. J., 2003, 64, 297-305.

70066 M. A. McCawley, M. S. Kent, and M. T. Berakis, Appl. Occup. Environ. Hyg., 2001, 16, 631-638.

67 A. B. Stefaniak, G. A. Day, M. D. Hoover, P. N. Breysse, and R. C. Scripsick, Toxicol. In Vitro., 2006, 20, 82-95.

68 D. Deubner, M. Kelsh, M. Shum, L. Maier, M. Kent, and E. Lau, 705 Occup. Environ. Med., 2000, 57, 133-139.

69 A. Profumo, G. Spini, L. Cucca, and M. Pesavento, Talanta, 2002, 57, 929-934.

70 Exposure Standards, Beryllium and Compounds, Australian Government, National Occupational Safety and Health Commission,

710 URL: www.nohsc.gov.au, accessed 30 March 2006

71 Occupational Hygiene Alert on Beryllium and Its Alloys, Industrial Accident Prevention Association, URL: www.iapa.ca, accessed 30 March 2006.

72 Proficiency Testing - Workplace Analysis Scheme for Proficiency, U.

$715 \quad$ K. Health and Safety Laboratory, URL: www.hsl.gov.uk, accessed 30 March 2006 


\section{TABLES}

Table 1 Method Detection Limit (MDL) for Beryllium Analytical Techniques ${ }^{\mathrm{a}}$

$\begin{array}{cccc}\text { Instrumentation } & \text { Estimated MDL }(\mu \text { g per sample) } & \text { Method } & \text { References } \\ \text { ICP-AES } & 0.009 & \text { ASTM D7035 } & 31 \\ \text { ICP-MS } & 0.001 & \text { EPA 200.8 } & 31 \\ \text { Graphite Furnace AAS } & 0.005 & \text { NIOSH 7102 } & 31 \\ \text { Atomic Fluorescence } & <0.002 & \text { ASTM D7202 }\end{array}$

${ }^{a}$ Values provided are examples of achievable MDLs as cited in the references. MDLs are specific to the measurement system involved, including instrumentation, sample matrix effects, and sample preparation.

Table 2 Reported Interferences on Primary Emission Lines for Beryllium ${ }^{a}$

\begin{tabular}{|l|l|}
\hline Beryllium Emission Line (nm) & Interfering Elements \\
\hline 313.042 & $\mathrm{~V}, \mathrm{Ti}$ \\
\hline 313.107 & $\mathrm{Al}, \mathrm{Cu}, \mathrm{Fe} \mathrm{Mn}, \mathrm{Mo}, \mathrm{Nb}, \mathrm{Ni}, \mathrm{Ti}, \mathrm{V}$ \\
\hline 234.861 & $\mathrm{Fe}, \mathrm{Ti}$ \\
\hline
\end{tabular}

${ }^{a}$ Based on Reference 21 (Winge et al) and survey data from Reference 22 (Brisson et al)

Table 3 Available Standard Methods for Preparation of Beryllium Workplace Monitoring Samples

\begin{tabular}{|l|l|l|l|}
\hline Sample Type & Sample Preparation Type & Available Sample Preparation Methods & References \\
\hline Air filter & Acid Digestion & $\begin{array}{l}\text { NIOSH 7102, NIOSH 7300, NIOSH 7303, OSHA ID-125G, } \\
\text { OSHA ID-206, HSE 29/2 (UK), INRS Fiche 003(France), } \\
\text { ASTM D7035, ISO 15202-2 }\end{array}$ & $\begin{array}{l}25,27,47-51, \\
53\end{array}$ \\
\hline Air filter & Extraction $^{a}$ & ASTM D7202 & 52 \\
\hline Surface wipe & Acid Digestion $^{a}$ & OSHA ID-125G, OSHA ID-206, NIOSH 9102 & $48,53 a$ \\
\hline Surface wipe & Extraction $^{a}$ & ASTM D7202 & 52 \\
\hline Bulk & Acid Digestion $^{2}$ & OSHA ID-125G, OSHA ID-206 & 48 \\
\hline
\end{tabular}

${ }^{a}$ Extraction method (1\% ammonium bifluoride) is specific for use with the atomic fluorescence method in ASTM D7202.

Table 4 Available Standard Methods for Analysis of Beryllium Workplace Monitoring Samples

\begin{tabular}{|l|l|l|l|}
\hline Sample Type(s) & Analytical Technique & Available Analysis Methods & References \\
\hline Air Filter & Graphite Furnace AAS & NIOSH 7102, HSE 29/2 (UK) & 27,49 \\
\hline Air Filter & ICP-AES & $\begin{array}{l}\text { ASTM D7035, ISO 15203-3, NIOSH 7300, NIOSH 7303, } \\
\text { EPA 6010B,EPA 200.7, OSHA ID-125G, OSHA ID-206 }\end{array}$ & $25,47-48,51,53-55$ \\
\hline Surface Wipe & ICP-AES & $\begin{array}{l}\text { EPA 6010B, EPA 200.7, OSHA ID-125G, } \\
\text { OSHA ID-206, NIOSH 9102 }\end{array}$ & $48,53 a, 54-55$ \\
\hline $\begin{array}{l}\text { Air Filter and } \\
\text { Surface Wipe }\end{array}$ & ICP-MS & EPA 6020, EPA 200.8 & 26,56 \\
\hline $\begin{array}{l}\text { Air Filter and } \\
\text { Surface Wipe }\end{array}$ & Fluorescence & ASTM D7202 & 52 \\
\hline Bulk & ICP-AES & OSHA ID-125G, OSHA ID-206 & 48 \\
\hline
\end{tabular}

